\title{
The Effects of Vitamin A Administration to Heifer and Pregnant Cow on the Changes of Hormonal and Body Weight
}

\author{
Sang-Rae Cho, Ui-Hyung Kim, Kuldeep Kumar, Seung-Hwan Lee, Myeung-Sik Lee, \\ Hyeon-Shup Kim, Hyun-Jae Lee and Byoung-Chul Yang ${ }^{\dagger}$ \\ Hanwoo Experimental Station, National Institute of Animal Science, RDA, Pyeongchang, 232-952 Korea
}

\begin{abstract}
The objective of this study was to investigate the interrelationship of weight and hormonal changes through the administration of vitamin A to first time pregnant heifers. A total of 28 Korean heifers was used for this study. The heifers were divided into two groups - with vitamin A $(n=14)$ and without vitamin A (control) $(n=14)$ in the feed. Body weight increased in vitamin A treated heifers starting 9 months until 15 months. After pregnancy, vitamin A treated heifers were found to maintain higher body weights than the control group. Pre-pregnancy and post pregnancy progesterone levels were not different between the two groups. Serum estradiol levels of heifers at different growth stages showed relatively higher E2 levels than the control. Also, the control during pregnancy may show higher serum E2 levels than the vitamin A treated heifers. The growth phase serum estradiol levels in heifers may be relatively higher than the control. During pregnancy it showed a similar trend. Serum levels of vitamin A treated heifers did not differ from pregnant heifers at 5 months of age. However, after 5 months from conception until 8 months of treatment it showed a high level. Serum cholesterol in pregnant cows was higher in the control group than the treatment from beginning until the end of pregnancy. This is considered to be related to fetus development during pregnancy, as well as the mother's health.
\end{abstract}

(Key words: progesterone, estradiol, cholesterol, vitamin A)

\section{INTRODUCTION}

Nutrition plays a primary role for the optimum expression of reproduction. Apart from energy and protein intake, the micronutrients (vitamins and minerals) are highly essential for better reproductive efficiency. Though these micronutrients are required in very minute quantities, they are considered indispensable for normal cellular metabolism, growth and maintenance including reproduction. The beneficial effects of vitamin $\mathrm{A}$ in controlling various maladies causing reproductive failure have been well documented (Yildiz et al., 2005).

Vitamin A is essential for the normal functioning of the retina, growth and differentiation of epithelial tissue, and embryonic development, reproduction and bone growth. It is highly essential for maintaining the health and integrity of epithelial tissues in the body. Vitamin A mostly converted by the mucosa of the small intestine and appears to be the most efficient provitamin (Hurley and Doane, 1989). Periparturient cows un- dergo intense mammary growth and marked production of colostrum rich in vitamin A during gestation, its circulatory levels decreases at the parturition, which is reported to predispose such animals to severe health problems including mastitis, retained placenta and metritis (Chawla and Kaur, 2004; Daniel et al., 1991). Progesterone is required for the maintenance of pregnancy in animals. It is a hormone with different actions dependent on the periods in the estrous cycle and regulates maturation of the oocytes, ovulation, myometrial quiescence, mammary gland growth and endometrial enzymes. Progesterone follows a regular pattern during pregnancy and declines in the prepartum period and at parturition in cattle. The natural progesterone levels in plasma show a large variation, depending on the species, sex, age and physiological status (Eissa et al., 1995; Silver, 1994; Yıldız and Çay, 2002). The objective of the study was to investigate the effects of vitamin A on the secretion of reproductive hormone for growth and physiology of pregnancy in the first administration to pregnant cattle. In

\footnotetext{
* This work was carried out with the support of the "Cooperative Research Program for Agriculture Science \& Technology Development (Project title: Research of estrus inhibit technical development at fattening in Hanwoo cattle, Project No. PJ010248)" Rural Development Administration, Republic of Korea.

+ Correspondence : bcyang@korea.kr
} 
addition, the aim of this study was to find out the interrelationship of weight and hormonal changes through the administration of vitamin A to first time pregnant heifers.

\section{MATERIALS AND METHODS}

The experiment was carried out using 28 female healthy Korean heifers of $150 \mathrm{~kg}$ body weight. Fourteen (14) heifers were treated with doses of vitamin A (Table 1), and another 14 served as control (without vitamin A). Body weight of control and treated animals were measured every month. Changes in progesterone level and estradiol levels were examined before and after pregnancy. Serum cholesterol and vitamin A levels were also examined every month during pregnancy for the hormonal changes.

To measure the level of vitamin $\mathrm{A}$ in plasma and activity of progesterone level and estradiol levels, blood was collected using heparinised vacutainer tubes. The plasma and the red blood cells were separated by centrifugation $(2,500 \mathrm{~g}$, for 15 $\min$ at $4{ }^{\circ} \mathrm{C}$ ). The plasma was frozen at $-20^{\circ} \mathrm{C}$ for further determination of vitamin A and other studies. These tests were done using different methods (Table 2).

\section{RESULT}

Body weight of heifers treated with vitamin A were signi-

Table 1. Doses of vitamin A according to body weight

\begin{tabular}{ccc}
\hline S. No. & Body weight & Dose of vitamin A \\
\hline 1 & $150 \mathrm{~kg}$ & $7,000 \mathrm{IU}$ \\
2 & $200 \mathrm{~kg}$ & $9,000 \mathrm{IU}$ \\
3 & $250 \mathrm{~kg}$ & $11,000 \mathrm{IU}$ \\
4 & $300 \mathrm{~kg}$ & $13,000 \mathrm{IU}$ \\
5 & $350 \mathrm{~kg}$ & $15,000 \mathrm{IU}$ \\
6 & $400 \mathrm{~kg}$ & $17,000 \mathrm{IU}$ \\
\hline
\end{tabular}

ficantly higher compared to normal animals before and after pregnancy (Fig. 1 (A) and (B)).

Progesterone level before pregnancy slightly increased with increasing body weight. The results indicate that values of progesterone increased slightly on the $1^{\text {st }}$ month of pregnancy, declined at $2^{\text {nd }}$ to $4^{\text {th }}$ months, increased sharply at $5^{\text {th }}$ month, peaked at $6^{\text {th }} \sim 7^{\text {th }}$ month, and then rapidly declined a day after parturition (Fig. 2 (A) and (B)).

In ovulatory cattle, estradiol concentration decreased during the $2^{\text {nd }}$ and $3^{\text {rd }}$ months and after that increased in non-treated animals without any regulation in the concentration of estradiol level (Fig. 3 (A) and (B)).

There were no significant changes on the concentration of vitamin A during pregnancy in non-treated cows (Fig. 4). The serum cholesterol in pregnant cows was higher in the control

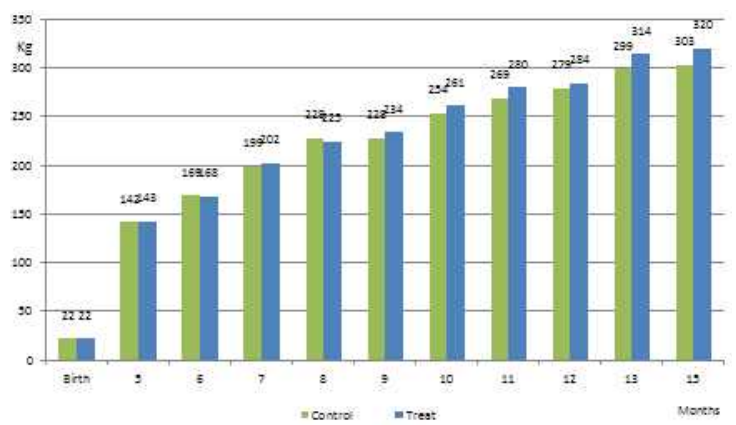

(A)

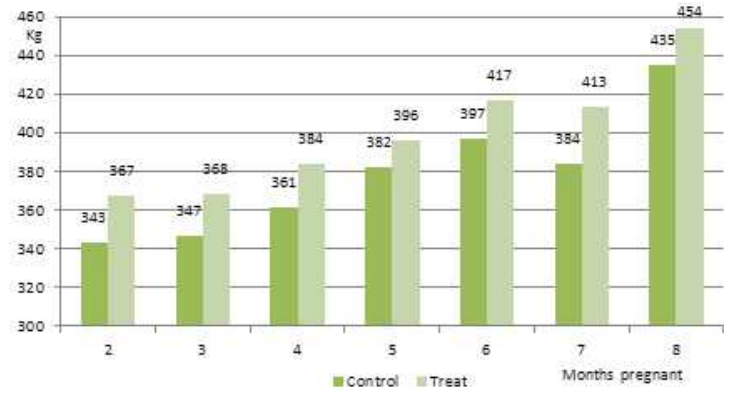

(B)

Fig. 1. Cattle heifers step-by-step weight change before $(A)$ and after pregnancy $(\mathrm{B})$.

Table 2. Test methods for the different hormones

\begin{tabular}{clccc}
\hline S. No & Test name & Test method & Test equipment & Reagent \\
\hline 1 & Progesteron & ECLIA & Cobas 6000 (Roche, Germany) & Progesteron (Roche, Germany) \\
2 & Estradiol & ECLIA & Cobas 6000 (Roche, Germany) & Estradiol (Roche, Germany) \\
3 & Vitamin A & HPLC & Agilent 1200 series HPLC/UV & \\
\hline
\end{tabular}




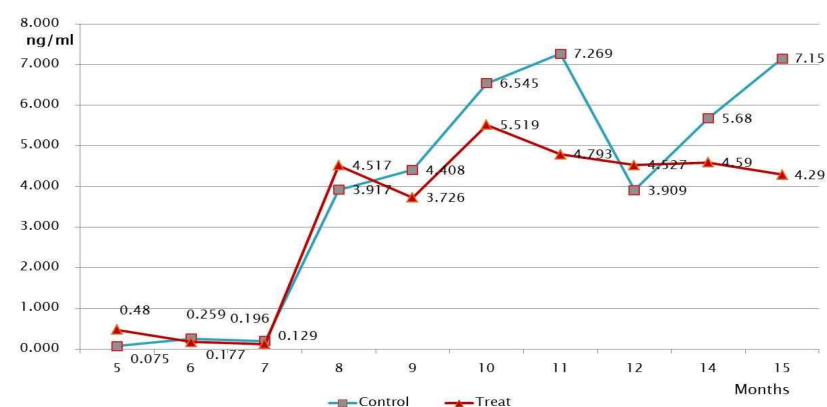

(A)

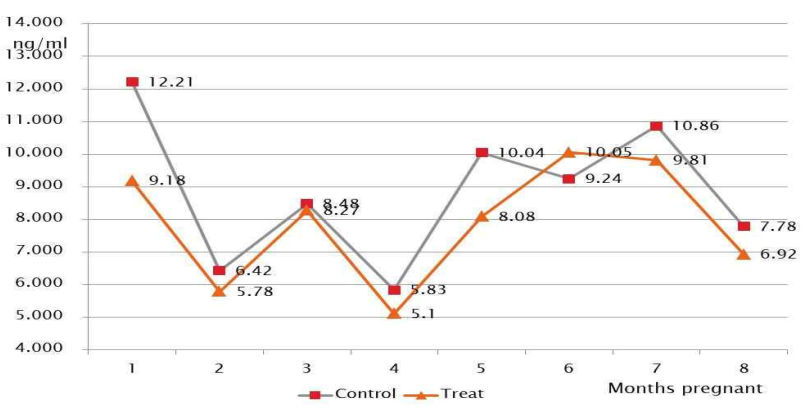

(B)

Fig. 2. Growth in heifers first pregnant cows (A) and serum progesterone levels (B).

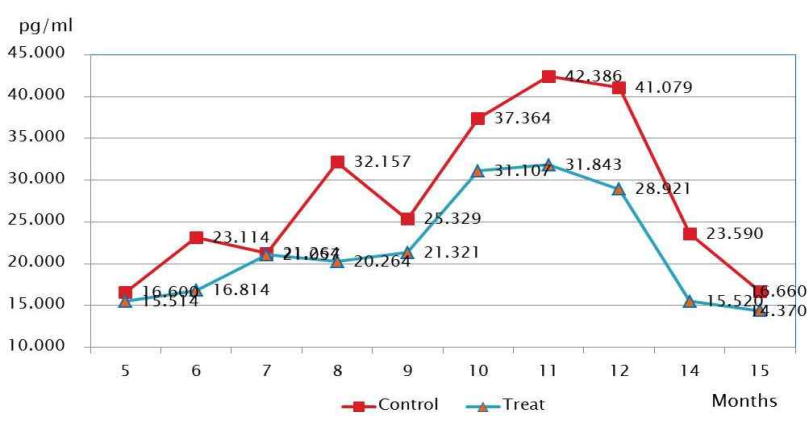

(A)

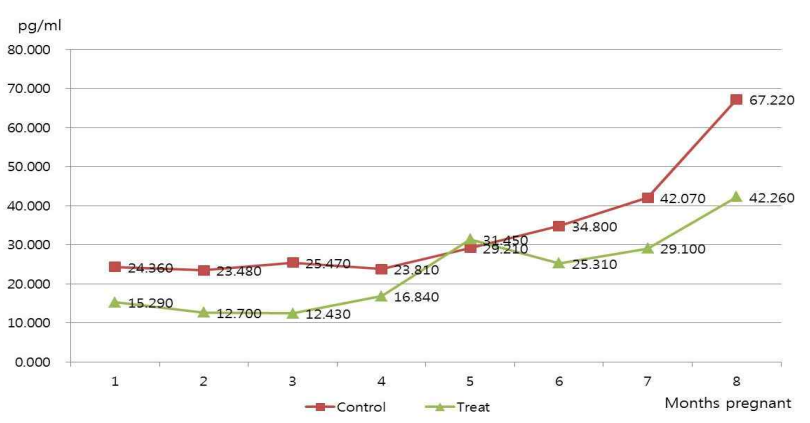

(B)

Fig. 3. Growth in heifers first pregnant cows (A) and serum estradiol levels (B)

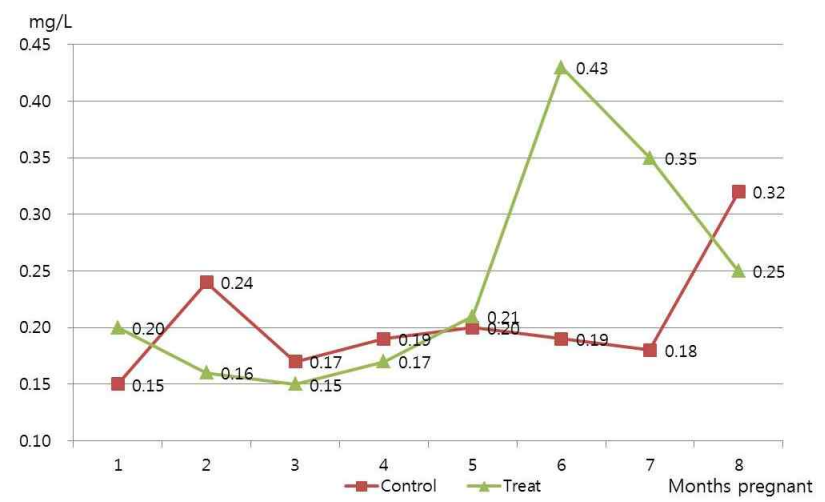

Fig. 4. Serum vitamin A level during pregnancy.

group than in the vitamin A treated animals from beginning until the end of pregnancy (Fig. 5).

\section{DISCUSSION}

Other than its positive effect on body weight, some researchers also found that vitamin A regulates vision, growth, and affects the overall health of animals (Zile and Cullum, 1983, Chew, 1987). It is very important for maintaining the health and integrity of epithelial tissues in the body.

The concentration of progesterone increased slightly during the first 2 months and 4 months of pregnancy (Eissa et al., 1995). Their values reached their peak levels on the $7^{\text {th }}$ month of the pregnancy period, decreased significantly at day 7 prepartumand dropped sharply after parturition. EissaandEl-Belely (1990) reported that the plasma concentrations of progesterone increased until the $3^{\text {rd }}$ month of gestation, then decreased significantly on the $4^{\text {th }}$ month. The higher values of progesterone during the first trimester of gestation might be associated with

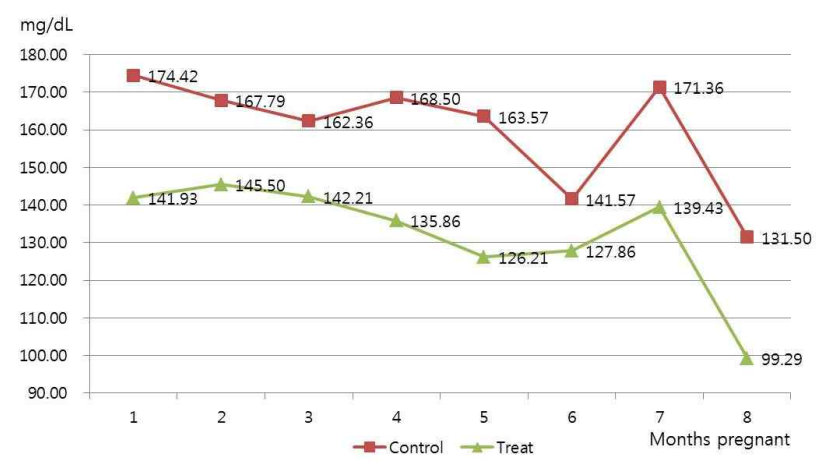

Fig. 5. Serum cholesterol level during pregnancy. 
the formation of accessory luteal tissue a rising from an ovulation which frequently occurs with in the gestation period. The findings are in agreement with earlier reports (EissaandElBelely, 1990, Mugerwa and Tegegne, 1989).

The increase in estradiol level with advancing pregnancy was reported in other domestic animals (Jain and Madan, 1989; Patel et al., 1992). Also, estradiol level rises in the latter part of gestation in cows (Hoffman et al., 1997).

From 3 to 6 months of pregnancy the concentration of vitamin A increased in treated animals which is similar to the earlier study of Haliloglu et al. (2002). They found that vitamin A levels in the plasma were influenced by the stage of the estrous cycle or pregnancy and were related to bovine luteal function.

The cholesterol level in seven-month pregnant heifers, after falling sharply in the control and treatment groups are common. Guedon et al. (1999) also reported significant decrease in cholesterol values at the end of pregnancy, were minimal (1.01 \pm $0.03 \mathrm{~g} / \mathrm{l})$ at parturition, and increased again up to $9^{\text {th }}$ week post calving. The serum non-esterified fatty acids (NEFA) and cholesterol concentrations have potential as indicators of disease risk in dairy cows (Kaneene et al., 1997). This is considered to be related to the fetus development during pregnancy, as well as the mother's health.

\section{CONCLUSION}

The data presented in this study showed that vitamin A could improve the productivity of the fetal bovine growth as well as progesterone production. Vitamin A as a primary therapeutic agent had strong effect on reproductive parameters. In this study, serum cholesterol levels in pregnant heifers showed very high level in the control group as compared to the treatment from beginning until the end of pregnancy. Therefore, administration of vitamin A during pregnancy will result in better maternal and fetal health. This is considered to be related to fetus development during pregnancy, as well as the mother's health. However from this study we conclude that more research is needed to evaluate of the relationship between these parameters and their effects on the bovine reproduction.

\section{REFERENCES}

Chawla R and Kaur H. 2004. Plasma antioxidant vitamin sta- tus of periparturient cows supplemented with a-tocopherol and $\beta$-carotene. Anim. Feed. Sci. Technol. 114:279-285.

Chew, BP. 1987. Vitamin A and $\beta$-carotene on host defense. J. Dairy. Sci. 70:2732-2743.

Daniel LR, Chew BP, Tanaka TS and Tjoelker LW. 1991. $\beta$ -Carotene and vitamin A effects on bovine phagocyte function in vitro during peripartum period. J. Dairy Sci. 74: 124-128.

Eissa HM, El-Belely MS, Ghoneim IM and Ezzo OH. 1995. Plasma progesterone, oestradiol-17beta, oestrone sulphate, corticosteroids and a metabolite of $\mathrm{PGF}_{2}$ alpha: evolation throughout pregnancy, before, during and after parturition in buffalo cows. Vet. Res. 26:310-318.

Eissa HM and El-Belely MS. 1990. Sequential changes in plasma progesterone, total oestrogens and corticosterioid in the cow throughout pregnancy and around parturition. Br. Vet. J. 146:24-29.

Guédon L, Saumande J, Dupron F, Couquet C and Desbals B. 1999. Serum cholesterol and triglycerides in postpartum beef cows and their relationship to the resumption of ovulation. Theriogenology 51:1405-1415.

Haliloglu S, Baspinar N, Serpek B, Erdem H and Bulut Z. 2002. Vitamin A and beta-carotene levels in plasma, corpus luteum and follicular fluid of cyclic and pregnant cattle. Reprod. Domest. Anim. 37:96-99.

Hamit Yildiz, Erdal Kaygusuzoğlu and Ömer Kizil. 2005. Concentration of serum vitamins $\mathrm{A}, \mathrm{E}$ and $\mathrm{C}$ and A- carotene during pregnancy in cows. Bull. Vet. Inst. Pulawy. 49:199202.

Hoffmann B, Wagner WC, Ratterberger E and Schmidt J. 1977. Endocrine relationship during late gestation and parturition in the cow. Ciba Founation Symo.: The Fetus and Bitrh, Amsterdam, Excerpta Medica. 47:107-122.

Hurley WL and Doane RM. 1989. Recent developments in the roles of vitamins and minerals in reproduction. J. Dairy Sci. 72:784-804.

Jain GC and Madan ML. 1989. Plasma prostaglandin F2, oestradiol-17B, cortisol and progesterone in animal parturient goats. Intern. J. Animm. Sci. 4:152-156.

Kaneene JB, Miller RAH, Thomas H and Gardiner JC. 1997. The association of serum nonesterified fatty acids and cholesterol, management and feeding practices with peripartum disease in dairy cows. Preventive Veterinary Medicine 31: 59-72. 
Mugerwa E and Tegegne A. 1989. Peripheral plasma progesterone concentration in zebu (Bos indicus) cows during pregnancy. Reprod. Nutr. Dev. 29:303-308.

Patel AV, Pathak MM and Mehta VM. 1992. Serum oestradiol levels around parturition stages in goats. Indian J. Animal Sci. 62:241-242.

Silver M. 1994. Placental progestagens in sheep and horse and the changes leading to parturition. Exp. Clin. Endocrinol. 102:203-211.

Y1ldı H and Çay M. 2002. Effect of oxytocin administered in the early stage of the oestrous cycle on the length of the oestrous cycle and levels of serum progesterone, plasma a vitamin and B-carotene in cows. Turk. J. Vet. Anim. Sci. 26:117-123.

Zile MH and Cullum ME. 1983. The function of vitamin A: Current concepts. Proc. SOC. Exp. Biol. Med. 172:138.

Received October 31, 2014, Revised November 28, 2014, Accepted December 10, 2014 